\title{
Correction to: Combining machine learning and texture analysis to differentiate mediastinal lymph nodes in lung cancer patients
}

\author{
Allan F. F. Alves ${ }^{1} \cdot$ Sérgio A. Souza ${ }^{2} \cdot$ Raul L. Ruiz Jr. $^{1} \cdot$ Tarcísio A. Reis $^{1} \cdot$ Agláia M. G. Ximenes $^{1} \cdot$ Erica N. Hasimoto ${ }^{1}$. \\ Rodrigo P. S. Lima ${ }^{1}$. José Ricardo A. Miranda ${ }^{2}$ - Diana R. Pina ${ }^{1}$ (i)
}

Published online: 6 April 2021

๑) Australasian College of Physical Scientists and Engineers in Medicine 2021

\section{Correction to: \\ Physical and Engineering Sciences in Medicine \\ https://doi.org/10.1007/s13246-021-00988-2}

In the initial online publication an author name and affiliation were misspelled. The original article has been corrected.

Publisher's Note Springer Nature remains neutral with regard to jurisdictional claims in published maps and institutional affiliations.

The original article can be found online at https://doi.org/10.1007/ s13246-021-00988-2.

Diana R. Pina

diana.pina@unesp.br

1 Medical School, Sao Paulo State University Julio de Mesquita Filho, Botucatu, Brazil

2 Institute of Bioscience, Sao Paulo State University Julio de Mesquita Filho, Botucatu, Brazil 